\title{
Selective adaptation of vowels
}

\author{
PHILIP A. MORSE, JONATHAN E. KASS, and RUBENS TURKIENICZ \\ University of Wisconsin, Madison, Wisconsin 59706
}

\begin{abstract}
Two experiments investigating the selective adaptation of vowels examined changes in listeners' identification functions for the vowel continuum [i-I- $\epsilon$ ] as a function of the adapting stimulus. In Experiment I, the adapting stimuli were [i], [I], and [ \& ]. Both the [i] and [ $\epsilon$ ] stimuli produced significant shifts in the neighboring and distant phonetic boundaries, whereas [I] did not result in any adaptation effects. In order to explore the phonetic nature of feature adaptation in vowels, a second experiment conducted using the adapting stimuli $[\mathrm{gig}]$ and $[\mathrm{g} \in \mathrm{g}]$, which differed acoustically from the [i] and [ ] vowels on the identification continuum. Only [gig] yielded reliable adaptation effects. The results of these experiments were interpreted as suggesting a relative rather than a stable auditory mode of feature analysis in vowels and a possibly more complex auditory feature analysis for the vowel [i].
\end{abstract}

According to recent studies of speech perception, infants as young as 1-2 months of age are able to discriminate important differences in the sounds of human speech. In the case of stop consonants, not only can infants discriminate the acoustic differences which signal voicing and place of articulation distinctions (Moffitt, 1971; Morse, 1972; Trehub \& Rabinovitch, 1972), but they also appear to discriminate these cues according to adult phonetic categories (Eimas, 1974, in press; Eimas, Siqueland, Jusczyk, \& Vigorito, 1971; Miller, 1974). Further, the development of these adult perceptual categories does not appear to depend on extensive experience in producing or perceiving a particular phonetic category. According to the findings of Kewley-Port and Preston (1974) and Pierce (1974), place of articulation and voicing contrasts do not emerge in the vocalizations of infants until several months after their ability to discriminate these contrasts. Although data on the distribution and frequency of speech sounds heard by the infant in the first few months is not yet available, cross-language studies of infant speech discrimination have revealed that infants are able to discriminate voicing differences not present in the language spoken by their parents (Eimas, in press; Lasky. Syrdal-Lasky, \& Klein, 1975; Streeter, 1974).

A more neurophysiological interpretation of the infant's categorical discrimination for stop consonants has recently been proposed by Eimas (1974). According to Eimas, the infant's "knowledge" of adult phonetic categories may depend upon auditory feature detector mechanisms which respond

This research was supported by NICHD Grants HD-01994, 1-P01-HD 08240-01, and 5-P01-HD-03352. The authors are indebted to David Pisoni and Janneane Gent for the generation of the synthetic stimuli and to Frank Cooper for the generous use of Haskins Laboratories in making the final tapes. Requests for reprints should be sent to Philip A. Morse, Department of Psychology. University of Wisconsin, Madison. Wisconsin 53706. selectively to specific phonetic features in the speech signal. The neurophysiology of these feature detectors is presumed to be similar to that observed in the auditory and visual systems of the monkey and frog (e.g., Frishkopf, Capranica, \& Goldstein, 1968; Wollberg \& Newman, 1972, and implicated in man's visual system (Blakemore \& Campbell, 1969). Indirect support for this phonetic feature detector hypothesis comes from studies of the selective adaptation of consonants in human adults (Cooper, 1974a; Cooper \& Blumstein, 1974; Eimas, Cooper, \& Corbit, 1973; Eimas \& Corbit, 1973). In this studies, the adults's identification responses (category boundaries) for stimuli along a given speech continuum (e.g., stimuli varying in voice onset time) are found to shift substantially when a particular syllable (e.g., [ba]) is rapidly presented for 1 or $2 \mathrm{~min}$. Presumably, this repeated presentation of a speech sound adapts or fatigues the detectors that are differentially sensitive to the acoustic and/or phonetic features of that sound. Since phonetic boundaries on a continuum (e.g., [ba-pa] on the voice-onset-time continuum) are thought to be determined by the equal activation of detectors for two different phonetic categories (Eimas \& Corbit, 1973), the fatiguing of one detector should result in a shift of the boundary toward the adapting stimulus.

Employing this adaptation procedure, Eimas 'and Corbit (1973) have reported that subjects adapted with [ba] shift their [ba-pa] category boundary toward the [ba] category relative to their preadaptation boundary, and those adapted with [pa] shift their [ba-pa] boundary toward [pa]. Furthermore, if the listener is adapted with [da] or [ta]. the [ba-pa] boundary is still shifted in the expected direction. Eimas and Corbit interpreted this latter result as suggesting that an abstract phonetic feature (voiced vs. voiceless) is being selectively adapted in these studies, not simply a specific acoustic stimulus selected from the continuum (e.g., [ba]). Similar adaptation results for place of articulation have been 
reported by Cooper (1974a) and Cooper and Blumstein (1974). In both studies, adaptation with [bae] produced a shift in the neighboring [bae-dae] boundary (toward [bae]), but not in the far [dae-gae] boundary. Furthermore, the same boundary shifts also obtained when subjects were adapted on a real speech [bi], [mae], and [vae]. Again, these results were interpreted as suggesting that adaptation also occurs at an abstract phonetic level for consonants having the same place of articulation, but which are not acoustically identical.

However, as several authors have pointed out (e.g., Diehl, 1975), the adaptation effects obtained in these voicing and place of articulation studies may have occurred at an auditory feature level rather than at a phonetic feature level. In other words, some of the acoustic cues for voicing and place of articulation were perhaps shared by both the adapting and the test stimuli in these studies. In addition, attempts to demonstrate reliable adaptation effects with the critical acoustic portion of these speech stimuli in isolation (e.g., with chirps and tweets) have generally yielded significant adaptation effects, although of a lesser magnitude than that observed for the entire syllable (e.g., Ades, 1973; Tartter \& Eimas, 1975). Furthermore, Ades (1974) observed that when the consonant-vowel (CV) stimuli [bae-dae-gae] were employed as adapting stimuli and the test continuum consisted of the same stimuli in reverse order (VC), no reliable adaptation effects were obtained for these same phonetic features. Similarly, Tash (1974) found that if the formant transitional cues for [bae] and [dae] were preceded by a steady-state vowel corresponding to the starting frequency of each transition, then these same auditory features yielded adaptation in the same direction as that obtained for the transition + vowel ([bae] and [dae]) stimuli, despite the fact that these terminal $F_{2}$ and $F_{3}$ transitions generally cue the opposite phonetic distinctions. Although these studies do demonstrate that a variety of auditory features may exhibit reliable adaptation effects, recent studies by Cooper (1974b) and Diehl (1975) have provided stronger evidence for phonetic feature adaptation for voicing and place of articulation using adapting stimuli which are signaled by entirely different acoustic cues than their phonetic counterparts on the test continuum (e.g., with burst vs. formant transition cues: Diehl, 1975). Thus, it appears that both auditory and phonetic levels of feature detectors are adaptable in adult listeners, but that many of the "phonetic" feature adaptation results reported in the literature may have been due instead to the adaptation of auditory features.

In summary, these adult adaptation data on stop consonants implicate the existence of complex auditory (and perhaps phonetic) feature detectors for both voicing and place which are behaviorally adaptable in the human adult. Eimas (1974) has recently proposed that these feature detectors may be important in the categorical discrimination of these contrasts in adults and that, furthermore, they may be responsible for the infant's ability to discriminate these consonant contrasts categorically at such an early age. Finally, Eimas (in press) has even suggested that the high-amplitude sucking (HAS) paradigm, employed in gathering much of the infant data on categorical discrimination, effectively adapts the infant to the preshift stimulus. Thus, these adult adaptation results are clearly important for our understanding of the infant speech perception data, not only because of the proposed neurophysiological basis of speech perception, but also because of the possibility that adaptation is a critical process in the HAS paradigm.

In contrast to these recent advances in our understanding of the perception of stop consonants in infants and adults, considerably less is known about the development of vowel perception. Studies of adult vowel perception initially have shown that the vowels $[i-I-\varepsilon]$ are generally perceived continuously rather than categorically (Fry, Abramson, Eimas, \& Liberman, 1962;Pisoni, 1973; Stevens, Liberman, Studdert-Kennedy, \& Öhman, 1969). Studies of infant vowel discrimination employing the HAS procedure have demonstrated that infants can discriminate large differences in vowels, such as [i] vs. [u] or [a] vs. [i] (Trehub, 1973), and most recently that they exhibit continuous discrimination for the vowels [i] vs. [I] (Swoboda, Morse, \& Leavitt, in press). However, no data are currently available on the selective adaptation of these vowels in adults. In view of the proposed relationships between the adult adaptation data for consonants and the categorical nature of the infant consonant discrimination data, the present set of adult vowel adaptation studies was undertaken in the hope of elucidating the basis for the continuous discrimination observed in the Swoboda et al. study of infant vowel discrimination. The vowels along the test continuum ([i-I- $\varepsilon])$ employed in the present studies may be characterized as sharing the features of "non-low" and "non-back" (Chomsky \& Halle, 1968) or of "unrounded" (Stevens, Liberman, Studdert-Kennedy, \& Öhman, 1969). Ladefoged (1975) described these vowels as sharing the feature of "front" and varying along a continuum from "high-front" ([i]) to "low-front" ([ $\varepsilon]$ ). The first study investigated the adaptation effect for the vowels [i], $[I]$, and $[\varepsilon]$ on the $[i-I-\varepsilon]$ continuum. The second study sought to explore vowel adaptation on a phonetic level by using the adapting stimuli [gig] and [geg] produced by a female instead of a male vocal tract. 


\section{EXPERIMENT I: ADAPTATION WITH [i], [I], AND [ह]}

\section{Method}

Stimuli. Thirteen steady-state vowels were synthesized with the tirst three formants varying in approximately equal logarithmic steps along the vowel continuum $[i-1-\varepsilon]$. The parameter values for each of the 13 stimuli are presented in Table 1 . The fourth and fifth formants were fixed at $3.500 \mathrm{~Hz}$ (F4) and $4.500 \mathrm{~Hz}$ (F5). The terminal fundamental frequency for each stimulus fell from 125 to $80 \mathrm{~Hz}$. These stimulus parameters are identical to those employed in Pisoni's (1971. 1973) studies of adult vowel perception and the Swoboda et al. study of infant vowel discrimination. The duration of each stimulus was $240 \mathrm{msec}$ (the same as that employed in the Swoboda et al. study). The three adapting stimuli, [i]. [I], and $[\varepsilon]$, employed in this experiment. consisted of Stimuli 1, 7, and 13, respectively, in Table 1 . All stinuli were originally synthesized at the M.I.T. Research Laboratory of Electronics by Pisoni (1971) and recorded on tape using the Haskins Laboratories PCM system.

Procedure. Baseline identitication responses were obtained from each subject tested individually in an unadapted state on the lst and 5 th day of the experiment. Each baseline session consisted of the 13 rousel stimuli in Table 1 randomized in 20 blocks to yitd a total of 260 stimuli. Each subject was instructed to identify each stimulus by circling on a prepared answer sheet either an " $\overline{\mathrm{E}}$ " (as in beet) an " $\mathrm{i} "$ (as in bit), or an "."." (as in bet). In order to acquaint the subject with the procedure, six practice trials were presented prior to the baseline sequence on Day 1 . The stimuli were presented with an interstimulus interval (ISI) of $3 \mathrm{sec}$ at a sound pressure level of approximately 65-70 dB (A). A Sony 756-2 tape deck, a Bogen Challenger amplifier, and an AR4x speaker were employed in playing the stimulus tapes to the subjects. All sessions were conducted in a sound-attenuated chamber.

On Days 2,3, and 4, the three adaptation tests, [i]. [I], and $[\varepsilon]$. were administered individually to subjects in counterbalanced order. Each adaptation test lasted approximately $1 \mathrm{~h}$ with a 24-h interval between each session. The adaptation procedure was patterned after that employed by Cooper (1974a) and Cooper and Blumstein (1974). Accordingly, in each adaptation session, the listener first received approximately $2 \mathrm{~min}$ of warm-up adaptation (200 presentations) on one of the three vowels with an ISI of 350 msec. Following this warm-up period and a 30-sec silent interval, the listener then received 33 adaptation trials. On each adaptation trial, the adapting stimulus was played for $1 \mathrm{~min}(100$ presentations. ISI $=350 \mathrm{msec}$ ), followed by $2 \mathrm{sec}$ of silence and then four randomly selected vowels from the vowel continuum in Table 1. During the 3 -sec interval between each of the four test stimuli. the listener was asked to identify the stimulus by circling the appropriate letter $(\bar{E}, i$, or $\breve{~})$ on the card prepared for that trial. After the fourth test stimulus in each trial was presented, $6 \mathrm{sec}$ of silence intervened before the onset of the next trial. The randomized order of the test stimuli was identical to that employed in the baseline sessions, except that only 10 tokens of each of the 13 vowels were presented. This resulted in a total of 130 test stimuli over the 33 trials, with the last trial consisting of only 2 test stimuli.

Subjects. Six undergraduate students at the University of Wisconsin served as subjects in this study. The subjects did not have any known hearing defects, and none had had any previous experience with synthetic speech. There were three males and three females. all between the ages of 19 and 22 . They were paid $\$ 2$ for each of the five sessions.

\section{Results and Discussion}

The baseline and adaptation results for Experiment $I$ are given in Table 2. The loci $(50 \%$ cross-over point) of the $[i-I]$ and $[I-\varepsilon]$ boundaries were estimated for each subject by first assigning each stimulus a number ranging from 1 to 13 , and then
Table 1

Formant Frequencies for Vowel Stimuli*

\begin{tabular}{cccc}
\hline $\begin{array}{c}\text { Stimulus } \\
\text { Number }\end{array}$ & $F_{1}$ & $\begin{array}{c}\text { Formant } \\
F_{2}\end{array}$ & $F_{\mathbf{3}}$ \\
\hline 1 & 270 & 2300 & 3019 \\
2 & 285 & 2262 & 2960 \\
3 & 298 & 2226 & 2902 \\
4 & 315 & 2180 & 2836 \\
5 & 336 & 2144 & 2776 \\
6 & 353 & 2103 & 2719 \\
7 & 374 & 2070 & 2666 \\
8 & 397 & 2032 & 2628 \\
9 & 420 & 1999 & 2581 \\
10 & 444 & 1966 & 2556 \\
11 & 472 & 1926 & 2544 \\
12 & 501 & 1898 & 2518 \\
13 & 530 & 1858 & 2492 \\
\hline
\end{tabular}

*From Pisoni (1971, 1973).

performing a least mean squares analysis (Ferguson, 1959) on the transformed percentages of each listener's identification responses [using the equation $Z=a+b$ (Vowel \#), with $Z=0$ ]. The loci for the two baseline conditions, BL1 and BL2 (conducted on Days 1 and 5), were computed separately for each listener. Since a $t$ test for correlated measures performed on the two baseline sessions revealed no significant differences, $\mathrm{p}>.05$, in either the [i-I] or $[1-\varepsilon]$ loci for BL1 vs. BL2, each listener's percentages were pooled to yield the average baseline loci $(\overline{\mathrm{BL}})$ for each subject.

The adaptation effect was assessed by first computing the loci of the $[\mathrm{i}-\mathrm{I}]$ and $[\mathrm{I}-\varepsilon]$ boundaries in each of the three adaptation conditions and then comparing these loci to the average baseline $(\overline{\mathrm{BL}})$ loci for each subject. Two-tailed $t$ tests for correlated measures were employed in assessing all baseline and adaptation measures. As can be seen in Table 2 , when the adapting stimulus was [i], the [i-I] boundary shifted from 6.15 to $4.97, \mathrm{t}(5)=2.83, \mathrm{p}<.05$, and the $[i-\varepsilon]$ boundary also shifted toward [i]: from 9.63 to $8.61, \mathrm{t}(5)=3.17, \mathrm{p}<.05$. Similarly, if subjects were adapted with $[\varepsilon]$, the $[I-\varepsilon]$ boundary shifted toward $[\varepsilon]: 9.63$ to $10.82, \mathrm{t}(5)=5.82, \mathrm{p}<.01$, and the $[\mathrm{i}-\mathrm{I}]$ boundary also shifted toward $[\varepsilon]: 6.15$ to $7.11, t(5)=$ $4.20, \mathrm{p}<.01$. Finally, when [I] was the adapting stimulus, neither the $[i-I]$ nor the $[I-\varepsilon]$ loci were significantly different from those obtained during $\overline{\mathrm{BL}}$, although examination of the [I] category data revealed a tendency for [I] to shrink with adaptation. This tendency was contirmed by a marginally significant $t$ test performed on the differences between the two boundaries ( $[\mathrm{i}-\mathrm{I}]-[\mathrm{I}-\varepsilon])$ for baseline vs. adaptation with $[\mathrm{I}], \mathrm{t}(5)=2.38, \mathrm{p}<.10$.

In general, the basic adaptation effects observed for the vowels in this study are consistent with those found for consonants varying in voicing and place of articulation. Adaptation of either $[i]$ or $[\varepsilon]$ resulted in a shift of the neighboring loci toward the adapting 
Table 2

Phonetic Boundaries for Baseline and Adaptation Conditions: Experiment I

\begin{tabular}{|c|c|c|c|c|c|c|}
\hline Subjects & BL-1 & $\mathrm{BL}-2$ & $\overline{\mathrm{BL}}$ & Adapt [i] & Adapt [I] & Adapt $[\epsilon]$ \\
\hline & \multicolumn{6}{|c|}{ [i-I] Locus } \\
\hline $\begin{array}{l}\text { S.B. } \\
\text { D.L. } \\
\text { P.G. } \\
\text { A.M. } \\
\text { M.M. } \\
\text { K.H. }\end{array}$ & $\begin{array}{l}6.05 \\
5.88 \\
6.71 \\
6.64 \\
5.57 \\
5.33\end{array}$ & $\begin{array}{l}6.12 \\
5.75 \\
7.57 \\
6.33 \\
5.81 \\
6.05\end{array}$ & $\begin{array}{l}6.12 \\
5.96 \\
7.02 \\
6.38 \\
5.67 \\
5.74\end{array}$ & $\begin{array}{l}3.05 \\
4.87 \\
6.90 \\
5.23 \\
5.18 \\
4.58\end{array}$ & $\begin{array}{l}5.65 \\
6.63 \\
7.28 \\
6.12 \\
6.18 \\
5.94\end{array}$ & $\begin{array}{l}6.76 \\
7.06 \\
8.89 \\
7.32 \\
6.70 \\
5.92\end{array}$ \\
\hline \multirow[t]{2}{*}{ Mean } & 6.03 & 6.27 & 6.15 & 4.97 & 6.30 & 7.11 \\
\hline & \multicolumn{6}{|c|}{ [I-e] Locus } \\
\hline $\begin{array}{l}\text { S.B. } \\
\text { D.L. } \\
\text { P.G. } \\
\text { A.M. } \\
\text { M.M. } \\
\text { K.H. }\end{array}$ & $\begin{array}{r}8.98 \\
9.34 \\
10.22 \\
9.55 \\
9.25 \\
8.12\end{array}$ & $\begin{array}{r}8.88 \\
14.46 \\
10.19 \\
10.76 \\
8.98 \\
9.29\end{array}$ & $\begin{array}{r}8.75 \\
10.82 \\
10.06 \\
10.32 \\
9.26 \\
8.57\end{array}$ & $\begin{array}{r}7.75 \\
10.00 \\
8.92 \\
7.91 \\
8.55 \\
8.55\end{array}$ & $\begin{array}{r}8.14 \\
10.00 \\
10.20 \\
8.10 \\
9.31 \\
8.43\end{array}$ & $\begin{array}{r}9.04 \\
12.36 \\
11.38 \\
11.31 \\
10.95 \\
9.88\end{array}$ \\
\hline Mean & 9.24 & 10.43 & 9.63 & 8.61 & 9.03 & 10.82 \\
\hline
\end{tabular}

stimulus. This resembles the shift observed in the [ba-pa] boundary by Eimas and Corbit (1973) when subjects were adapted with either [ba] or [pa]. It is also similar to Cooper's (1974a) finding of a shift in the [bae-dae] locus with adaptation on [bae] and in the [dae-gae] locus when [gae] was the adapting stimulus.

However, the adaptation effects for vowels appear to differ in two important ways from those observed for stop consonants. First, no reliable adaptation effect obtained for the middle category [I], whereas Cooper (1974a) reported that adaptation with [dae] shifted both the [bae-dae] and [dae-gae] locus toward [dae]. The absence of an adaptation effect for [I] suggests that listeners may have regarded [I] as a "middle" category "somewhere" along a continuum between the two extremes [i] and $[\varepsilon]$, thus possessing somewhat less distinctive boundaries. Secondly, adaptation on [i] and $[\varepsilon]$ produced not only a reliable shift in the neighboring boundary, but it consistently resulted in a significant shift in the distant locus as well. In contrast, Cooper's study of the [bae-dae-gae] continuum indicated that the adaptation effects for stops were quite stable and did not extend to the far boundary. ${ }^{1}$ Additional evidence for the stability of the far locus in consonant adaptation has recently been reported by Tartter and Eimas (1975). Using [bae] as the adapting stimulus and [bae-dae-gae] as the test continuum, these authors failed to observe any suggestion of a shift in the [dae-gae] boundary, despite a reliable shift in the [bae-dae] boundary.

Thus, in contrast to the more stable feature analyzing system observed by Cooper (1974a) and Tartter and Eimas (1975) for stop consonants, the results of this study suggest that a relative mode of feature analysis prevails for $240-\mathrm{msec}$ vowels. This relativity in the feature adaptation of vowels is consistent with other differences observed between stop consonants and vowels. First of all, the differences in the articulatory categories $[i-I-\varepsilon]$ are much more gradual than the more abrupt differences observed for place of articulation in [bae-dae-gae]. Consequently, [I] may be perceived as occupying more of a "middle" position along a continuum than is the case for [dae]. Secondly, although studies of categorical perception have demonstrated that consonants are generally perceived more categorically than vowels (Pisoni, 1971, 1973; Stevens, Liberman, Studdert-Kennedy, \& Öhman, 1969), the withincategory discrimination of vowels is much more susceptible to experimental manipulations which increase the listener's access to his auditory short-term memory for speech stimuli (Pisoni, 1973, 1975). Consequently, vowels may become more or less categorically discriminated under a range of conditions which do not affect the categorical discrimination of stop consonants. Thus, relativity in vowel perception (compared to the stability of consonant categories) is not unique to the adaptation data obtained in the present experiment, but receives some support from other observations of speech perception and production.

\section{EXPERIMENT II: PHONETIC FEATURES IN VOWEL ADAPTATION?}

Although feature detectors may be functional at several auditory levels of analysis for stop consonants (cf. Cooper, 1975), some adaptation studies have provided strong support for phonetic feature detectors for voicing and place of articulation (Cooper, 1974b; Diehl, 1975). For example, Diehl (1975) observed reliable adaptation effects using a place contrast signaled by burst cues in the adapting stimuli (e.g., $[t \varepsilon])$ and only formant transition cues in the test 



first vowel experiment in the present study provide evidence for auditory feature detectors in vowels, but this experiment did not investigate feature adaptation in vowels at a phonetic level. Consequently, a second experiment was conducted to explore one aspect of phonetic adaptation effects in vowels. Toward this purpose, two adapting vowel stimuli were employed which differed acoustically from their phonetic counterparts along the same $[i-[-\varepsilon]$ test continuum.

\section{Method}

Stimuli. The test stimuli consisted of the same series of 13 synthetic vowel stimuli employed in Experiment I. The adapting stimuli were selected to be maximally different acoustically from the [i] and $[\varepsilon]$ ends of the test continuum. Since rapid articulation of vowels in a CVC context (Lindblom \& Studdert-Kennedy, 1967) and a female fundamental frequency/vocal tract (Peterson \& Barney, 1952) are known to result in vowels whose formant frequencies differ considerably from the steady-state vowels produced by a male speaker (the 13 test stimuli), a natural speech [gig] and [geg] produced by a female speaker were used as the adapting stimuli. Spectrograms of these stimuli revealed that the approximate formant frequencies for these stimuli at the point of closest approach to vowel target were as follows: [i] $-\mathrm{F} 1=300 \mathrm{~Hz}$, $\mathrm{F} 2=2.600 \mathrm{~Hz}, \mathrm{~F} 3=3.300 \mathrm{~Hz} ;[\varepsilon]-F 1=700 \mathrm{~Hz}, \mathrm{~F} 2=$ $2.400 \mathrm{~Hz}, \mathrm{F3}=3.000 \mathrm{~Hz}$. The duration of both stimuli was approximately $340 \mathrm{msec}$, including the final release burst (the unreleased portion was completed within the first $200 \mathrm{msec}$ ). Postexperimental questioning of the subjects revealed that all six subjects heard the vowel in [ $g \varepsilon g]$ as $[\varepsilon]$ and four of the six heard [i] in [gig]; the remaining two heard the vowel [1].

Procedure and Subjects. The baseline and adaptation procedures were essentially those described in Experiment 1 , except that only 2 days of adaptation testing were given to each listener: one for [gig] and one for [gॄg]. counterbalanced over subjects. Furthermore, in the $2 \cdot$ min warmup and $1-\mathrm{min}$ adaptation sequences, the subjects heard 170 and 85 tokens, respectively, of the adapting stimulus. Six different listeners (three male. three female) between the ages of 19 and 22 served as paid subjects.

\section{Results and Discussion}

The baseline identification and adaptation data for Experiment II are presented in Table 3. Since no reliable difference was observed between the two baselines, $\mathrm{p}>.05, \mathrm{BL} 1$ and BL2 were pooled to yield an average baseline $(\overline{\mathrm{BL}})$ for each subject. $T$ tests for correlated measures (two-tailed) revealed that the adapting stimulus [gig] significantly shifted both the [i-I] boundary, $\mathrm{t}(5)=2.80, \mathrm{p}<.05$, and the [I- $\varepsilon]$ boundary, $\mathrm{t}(5)=3.01, \mathrm{p}<.05$, toward the [i] category. In contrast, adapting the listener with [ggg] did not result in a reliable shift in either the [i-I] or $[\mathrm{I}-\varepsilon]$ boundary $(\mathrm{p}>.20)$.

These findings raise a number of questions about the possible auditory vs. phonetic features underlying the perception of [i] and [ $\varepsilon$ ]. First, let us consider [geg] and the absence of the adaptation effects previously observed for $[\varepsilon]$ in Experiment $I$. Inspection of the estimated formant frequencies for [geg] reveals that the vowel in this stimulus contained F1, F2, and F3 values which differed considerably from those of the
Table 3

Phonetic Boundaries for Baseline and Adaptation Conditions: Experiment II

\begin{tabular}{lrrrrr}
\hline $\begin{array}{l}\text { Sub- } \\
\text { jects }\end{array}$ & BL-1 & BL-2 & $\bar{B} \bar{L}$ & $\begin{array}{r}\text { Adapt- } \\
\text { [gig] }\end{array}$ & $\begin{array}{r}\text { Adapt- } \\
\text { [geg] }\end{array}$ \\
\hline \multicolumn{5}{c}{} \\
A.K. & 7.34 & 6.71 & 7.14 & 6.01 & 6.10 \\
S.T. & 6.96 & 4.99 & 6.02 & 5.90 & 7.05 \\
P.R. & 6.63 & 6.97 & 6.71 & 5.99 & 6.70 \\
A.M. & 6.09 & 5.90 & 6.04 & 5.93 & 6.25 \\
S.F. & 6.37 & 5.78 & 6.20 & 5.80 & 5.86 \\
L.L. & 6.17 & 5.40 & 5.89 & 5.45 & 5.12 \\
Mean & 6.59 & 5.96 & 6.33 & 5.85 & 6.18 \\
& & & {$[1+]$ Locus } & & \\
A.K. & 10.73 & 9.07 & 10.04 & 9.62 & 9.27 \\
S.T. & 9.76 & 9.00 & 9.46 & 9.08 & 11.42 \\
P.R. & 11.48 & 9.12 & 10.55 & 9.60 & 10.07 \\
A.M. & 8.51 & 8.30 & 8.50 & 8.07 & 8.98 \\
S.F. & 9.72 & 9.49 & 9.68 & 9.74 & 10.83 \\
L.L. & 8.61 & 8.59 & 8.73 & 8.26 & 9.76 \\
Mean & 9.80 & 8.93 & 9.49 & 9.06 & 10.06 \\
\hline
\end{tabular}

adapting [ $\varepsilon$ ] stimulus of Experiment I. In fact, [geg]'s values not only fell completely outside of the formant frequencies for any of the stimuli in the $[\varepsilon]$ test category, but they were actually closer to those for [i] than for $[\varepsilon]$. In addition, the differences between formants increased from approximately $1,330 \mathrm{~Hz}([\varepsilon])$ to $1,700 \mathrm{~Hz}$ ([gعg]) for $\mathrm{F} 1-\mathrm{F} 2$, but remained approximately the same for the F2-F3 difference $(700 \mathrm{~Hz})$. Thus, although [geg] and $[\varepsilon]$ both contained the same phonetic event $[\varepsilon]$, they did not share any important acoustic characteristics. Therefore, the failure to obtain similar adaptation effects for [geg] and $[\varepsilon]$ indicates that auditory rather than any type of phonetic feature detectors were responsible for the adaptation effects observed with this vowel.

In contrast, [gig] did yield the same adaptation effects observed for [i] in Experiment I, although the magnitude of these effects was not as great as those evidenced for [i]. Inspection of the estimated target frequencies of the three formants of [gig] reveals that the vowel in this stimulus also contained formant values which were different from those of the adapting [i] in Experiment $I$. In addition, the formant frequencies for $F 2$ and $F 3$ fell outside of the [i] test category (in a more extreme [i] direction). As in the case of [geg], the F2-F3 difference was similar for both [gig] and [i] (approximately $700 \mathrm{~Hz}$ ), but the F1-F2 difference increased from $2,000 \mathrm{~Hz}$ for [i] to $2,300 \mathrm{~Hz}$ for [gig]. Although [gig] differed from the [i] test category on a number of important acoustic features, the estimated F1 frequency for [gig] did fall within the $F 1$ values of the [i] test category. However, it is not $F 1$ by itself, but generally the acoustic difference between F1 and F2 (which was not similar for [gig] and [i]) that has been found to be critical in categorical judgments of vowels (Peterson \& Barney, 1952). In addition, this 
overlap in the $F 1$ values of [gig] and the [i] test category must not be overemphasized because of the difficulties encountered in estimating the F1 target frequencies of the rapidly articulated [gig]. Since F1 was very low in frequency for [gig], it was particularly difficult to determine spectrographically its exact center value. This is significant, because an error of 75-100 $\mathrm{Hz}$ could place the vowel in [gig] in the [I] category. The fact that one-third of the subjects in this experiment labeled the vowel in [gig] as [I] further suggests a need for caution in interpreting this similarity in $F 1$ values.

In summary, the results of this second experiment reveal that the $[\varepsilon]$ adaptation effects observed in Experiment I were dependent on auditory feature detectors. In contrast, the reliable adaptation effects obtained for [gig] suggest the possibility that more complex auditory (or perhaps even phonetic) feature detectors may govern the perception of [i]. Additional investigations in which $F 1$ is systematically varied and/or F2 and F3 fall more within the [I] range may help to clarify these feature-level differences.

In addition to the possible suggestion of differential vowel adaptation effects for [i] (vs. $[\varepsilon]$ ), several other observations in the vowel literature have also implicated [i] as a "special" vowel. First, a recent investigation of categorical discrimination in our laboratory with 8-week-old infants (Swoboda, Morse, $\&$ Leavitt, in press) revealed a tendency for infants to discriminate changes in $240-\mathrm{msec}$ vowels which occurred in the direction of the [i] category (e.g., [i] $\rightarrow$ [I]). However, when these same vowels were shortened from 240 to $80 \mathrm{msec}$, this tendency became highly significant, for both between- and withincategory changes (Swoboda, Kass, Morse, \& Leavitt, Note 1). Thus, infants appear to treat [i] differently from its neighbor [I]. This special status of [i] is also suggested by its membership as a cardinal vowel in the universal vowel triangle: [i], [a], [u]. As such, [i] represents an extreme articulatory position in the human vocal tract. In addition, it appears to permit much more variation than $[I]$ or $[\varepsilon]$ in its production, while still retaining its perceptual identity (Stevens, 1972). Thirdly, Lieberman (1974) has suggested that the three cardinal vowels are unique phylogenetic acquisitions in human speech and that these vowels play a critical role in speech perception by allowing listeners to "calibrate" the vocal tract of a speaker, thereby enabling them to decode the other segmentals in that speaker's speech. Thus, several different lines of evidence conspire to suggest that the vowel [i] may possess a special status among the vowels on the $[i-I-\varepsilon]$ continuum. Perhaps this differential status is related to the ability of [i] (and not $[\varepsilon]$ ) to yield reliable adaptation effects in spite of important acoustic variations in its structure.
In summary, the results of these two experiments indicate that the adaptation of vowels produced significant shifts in category boundaries, similar to those reported for stop consonants. However, in contrast to the stable feature system evidence in consonant adaptation studies (e.g., Cooper, 1974a), vowels exhibit a relative underlying feature system. This relative feature system is reflected in the near and distant boundary shifts observed for the [i] and $[\varepsilon]$ adapting stimuli and the absence of any adaptation effects for the middle category, [I]. The failure of [gघg] to demonstrate any reliable adaptation effects indicates that auditory feature detectors are responsible for the adaptation effects with [ $[\varepsilon]$. In contrast, the significant adaptation results for [gig] suggest a possibly more complex auditory feature analysis for the [i] vowel. The feature analysis for [i] may be "phonetic" in the present study only to the extent that two acoustically different stimuli which share the same phonetic event, [i], yield reliable adaptation effects. However, the present set of experiments did not explore the adaptation of phonetic features in vowel perception. Such a study would require the demonstration of feature detectors in vowel adaptation which are analogous to the "labial" or "voiceless" features posited for consonants. Within the Chomsky-Halle feature system, [i], [1], and [ $[\varepsilon]$ are considered -back and -low. Since the [i] and $[\varepsilon]$ adapting stimuli produced opposite adaptation effects, the results of the present study suggest that phonetic feature detectors for either of these features are unlikely. These opposite effects are probably not due to phonetic feature detectors for tense vs. lax $([i]=+$ tense, $[\varepsilon]=$ -tense), since [I] is also -tense and it did not result in the same adaptation effects as $[\varepsilon]$. Similarly, these opposite effects are unlikely due to differences in height $([\mathrm{i}]=+$ high, $[\varepsilon]=-$ high), since $[\mathrm{I}]$ is also thigh. However, it is possible that height is really a continuum underlying vowel distinctions (as Ladefoged, 1975, depicts the vowel space) and that [I] is simply not an extremely high vowel as is [i]. Thus, adaptation with another very "high" vowel (e.g., [u]) might provide a better test of this phonetic feature. In conclusion, evidence for phonetic feature detectors in vowel adaptation requires adaptation with vowels which not only differ acoustically, but also phonetically from the test continuum. The present study, although intimating that complex auditory feature detectors may differ for the phonetic event [i] than for $[\varepsilon]$, did not directly test for underlying phonetic features in vowel adaptation. However, the results of this study do suggest that a closer examination of phonetic feature adaptation in vowels may fail to demonstrate phonetic feature detectors responsive to many of the vowel features in the Chomsky-Halle system. 


\section{REFERENCE NOTE}

1. Swoboda, P., Kass. J.. Morse. P., \& Leavitt, L. Memory factors in infant vowel discrimination. In preparation.

\section{REFERENCES}

ADEs, A. Some effects of adaptation on speech perception. M.I.T. Research Laboratory of Electronics Quarterly Progress Report, 1973, 111, 121-129.

ADEs. A. How phonetic is selective adaptation? Experiments on syllable position and vowel environment, Perception \& Psychophysics, 1974, 16. 61-66.

Blakemore, C.. \& Campbell, F. On the existence of neurons in the human visual system selectively sensitive to the orientation and size of retinal images. Journal of Physiology, 1969, 203, 237-260.

Chomsky, N., \& Halle, M. The sound pattern of English. New' York: Harper and Row, 1968.

COOPER, W. Adaptation of phonetic feature analyzers for place of articulation. Journal of the Acoustical Society of America, 1974, 56, 617-627. (a)

Cooper, W. Selective adaptation for acoustic cues of voicing in initial stops. Journal of Phonetics, 1974. 2. 303-313. (b)

CoOper. W. Selective adaptation to speech. In F. Restle, R. Shiffrin. N. Castellan, H. Lindman, \& D. Pisoni (Eds.), Cognitive theory (Vol. 1). Potomac, Md: Erlbaum, 1975.

CoOper. W., \& Blumstein, S. A "labial" feature analyzer in speech perception. Perception \& Psychophysics, 1974, 15. $591-600$.

DIEHL, R. The effect of selective adaptation on the identification of speech sounds. Perception \& Psychophysics, 1975, 17, 48-52.

Eimas, P. Auditory and linguistic processing of cues for place of articulation by infants. Perception \& Psychophysics, 1974, 16, 513-521.

EImas, P. Speech perception in early infancy. In L. Cohen \& P. Salapatek (Eds.), Infant perception. New York: Academic Press, in press.

Eimas, P.. Cooper, W., \& Corbit, J. Some properties of linguistic feature detectors. Perception \& Psychophysics, 1973. 13. 247-252.

Eimas, P.. \& Corbit. J. Selective adaptation of linguistic feature detectors. Cognitive Psychology, 1973, 4, 99-109.

Eimas, P., Siqueland, E.. Jusczyk, P., \& Vigorito, J. Speech discrimination in infants. Science, 1971. 171, 303-306.

Ferguson. G. Statistical analysis in psychology and education. New York: McGraw-Hill, 1959. Pp. 118-121.

Frishkopf, L.. Capranica, R., \& Goldstein, M. Neural coding in the bullfrog's auditory system: A teleological approach. Proceedings of the IEEE, 1968. 56, 969-980.

Fry, D., abramson, A., Eimas, P., \& Liberman, A. The identitication and discrimination of synthetic vowels. Language and Speech, 1962. 5, 171-189.

Kewley-Port, D., \& Preston, M. Early apical stop production: A voice onset time analysis. Journal of Phonetics, 1974, 2. 195-210.

LADEFoged. P. A course in phonetics. New York: Hatcourt Brace Iovanovich. 1975.

Lasky, R., Syrdal-Lasky, A., \& Klein, R. VOT discrimination by four to six month old infants from Spanish environments. Journal of Experimental Child Psychology, 1975, 20. 215.225.

LiEBERman, $P$. On the evolution of language: A unified view. Cognition. 1974, 3. 59-94.
Lindalom, B., \& Studdert-Kennedy, M. On the role of formant transitions in vowel recognition. Journal of the A coustical Society of America, 1967, 42, 830-843.

Miller. J. Phonetic determinants of infant speech perception. Unpublished doctoral dissertation. University of Minnesota, 1974.

Moffirt, A. Consonant cue perception by twenty-to-twenty-four week-old infants. Child Development, 1971, 42, 717-731.

MORSE, P. The discrimination of speech and nonspeech stimuli in early infancy. Journal of Experimental Child Psychology, $1972,14,477.492$.

Peterson, G., \& Barney, H. Control methods used in a study of the vowels. Journal of the Acoustical Society of America, 1952, 24, 175-184.

PiERCE, J. A study of 750 Portland, Oregon children during the first year. Stanford University Papers \& Reports on Child Language Development. 1974, 8, 19-25.

PisonI, D. On the nature of categorical perception of speech sounds. Unpublished doctoral dissertation, University of Michigan, 1971.

Pisoni, D. Auditory and phonetic memory codes in the discrimination of consonants and vowels. Perception \& Psychophysics, 1973, 13, 253-260.

Pisoni, D. Auditory short-term memory and vowel perception. Memory \& Cognition, 1975, 3, 7-18.

Stevens, $K$. The quantal nature of speech: Evidence from articulatory-acoustic data. In P. Denes \& E. David (Eds.), Human communication, a unified view. New York: McGraw-Hill, 1972. Pp. 51-66.

Stevens, K., Liberman, A., Studdert-Kennedy, M., \& Öhman, S. Cross language study of vowel perception. Language and Speech, 1969, 12, 1-23.

STREETER, L. The effects of linguistic experience on phonetic perception. Unpublished doctoral dissertation, Columbia University, 1974.

Swoboda, P., Morse, P., \& Leavirt, L. Continuous vowel discrimination in normal and at risk infants. Child Development, in press.

TARTERR. V.. \& EIMAs. P. The role of auditory feature detectors in the perception of speech. Perception \& Psychophysics, 1975, 18, 293-298.

TAsH. J. Selective adaptation of auditory feature detectors in speech perception. Unpublished Masters thesis, Indiana University. 1974.

Trenub. S. Infants' sensitivity to vowel and tonal contrasts. Developmental Psychology, 1973, 9, 91-96.

TrehuB, S., \& Rabinovitch, S. Auditory-linguistic sensitivity in early infancy. Developmental Psychology, 1972, 6, 74-77.

Wollberg, Z., \& Newman, J. Auditory context of squirrel monkey: Response patterns of single calls to speciesspecific vocalizations. Science, 1972, 175, 212-214.

\section{NOTE}

1. Cooper (1974) did report some "suggestion" to the contrary when [gae] was the adapting stimulus (one-tailed $t$ test). but since this marginal finding was not confirmed in his discrimination results, it was discounted in subsequent discussions.

(Received for publication June 4, 1975; revision received October 20, 1975.) 